\title{
Na superfície da areia o movimento efêmero do desenho
}

\author{
Elaine Schmidlin (UDESC) \\ Sandra Maria Correia Favero (UDESC)
}

\begin{abstract}
RESUMO
O texto aborda o desenho na superfície da areia observados em percursos estéticos realizados no Pontal da Daniela situado em Florianópolis, Santa Catarina. Em práticas artísticas pela orla da praia, registrou-se imagens fotográficas dos rastros de pequenas espécies, habitantes deste lugar, que configuravam desenhos singulares e espontâneos sem interferências humanas. No processo da escrita, entre articulações filosóficas e poéticas, apresentam-se essas imagens em atravessamentos com as noções de invisibilidade e visibilidade, presentes na linguagem do desenho em Jacques Derrida, e com a configuração de uma quase virtualidade em modos de ver de David Lapoujade. Finalmente, a configuração do trabalho propõe trazer os esboços que se desenham e se inscrevem no território arenoso, intensificando suas existências mínimas.
\end{abstract}

PALAVRAS-CHAVE: Desenho; Invisibilidade; Visibilidade; Virtualidade.

\section{ABSTRACT}

This paper addresses the design on the sand surface observed in aesthetic journeys made in Pontal da Daniela located in Florianopolis, Santa Catarina. In artistic practices by the edge of the beach, there was photographic images of small species of trails, inhabitants of this place that made up natural and spontaneous drawings without human interference. In the process of writing, between philosophical and poetic articulations, these images are presented in intersections with the notions of invisibility and visibility, present in the drawing language in Jacques Derrida, and with the configuration of an almost virtuality in David Lapoujade's views. Finally, the configuration of the work proposes to bring the sketches that are drawn and inscribed in the sandy territory, intensifying their minimum existences.

KEYWORDS: Drawing; Invisibility; Visibility; Virtuality.

No cosmos das coisas, há aberturas, inúmeras aberturas desenhadas pelos virtuais. Raros são aqueles que as percebem e lhes dão importância; mais raros ainda aqueles que exploram essa abertura em uma experimentação criadora.

David Lapoujade (2017, p.44)

Lapoujade, com referências em obras de Éthienne Souriau ${ }^{1}$, refere-se aos inúmeros pontos de vista que existem a seu modo em uma virtualidade que não se percebe, tal qual um caminhante

\footnotetext{
${ }^{1}$ Filósofo francês (26/04/1892 - 19/11/1979), especialista em Estética, que em 1938 fez o inventário de diferentes modos de existência que povoam o mundo, particularmente, a classe dos seres virtuais. (LAPOUJADE, 2017)
}

DOI : $10.5965 / 24471267522019116$

http://dx.doi.org/10.5965/24471267522019116 


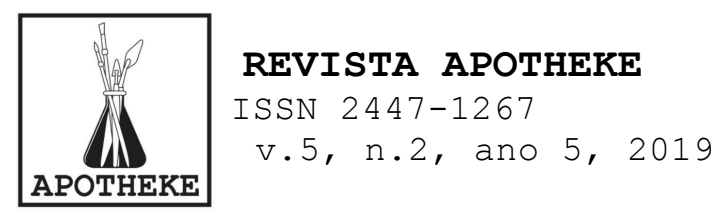

distraído, que não consegue ver uma sucessão de pedras que atravessa um riacho ou mesmo observar outros detalhes que a natureza oferece aos sentidos. Desse modo, especialmente no âmbito deste texto, pretende-se dar visibilidade as inúmeras manifestações de rastros espontâneos deixados por existências mínimas nas areias da orla da praia. Em percursos estéticos, esses rastros se tornam aparição, pois o que aparece é o modo de existência que the é próprio sob outro ponto de vista, a configuração de um desenho. Nesse ponto de vista, como apreender o fenômeno dos rastros como animado por uma perspectiva própria? Perceber, para Souriau segundo Lapoujade, "não é observar de fora um mundo estendido diante de si, pelo contrário, é entrar num ponto de vista" (2017, p.47). Desse modo, a percepção se torna uma espécie de participação em que:



Na superfície da areia entramos em um ponto de vista com a paisagem de pequenos rastros deixados na areia por pequenas existências mínimas que, em uma aparição sutil, configuram desenhos. 


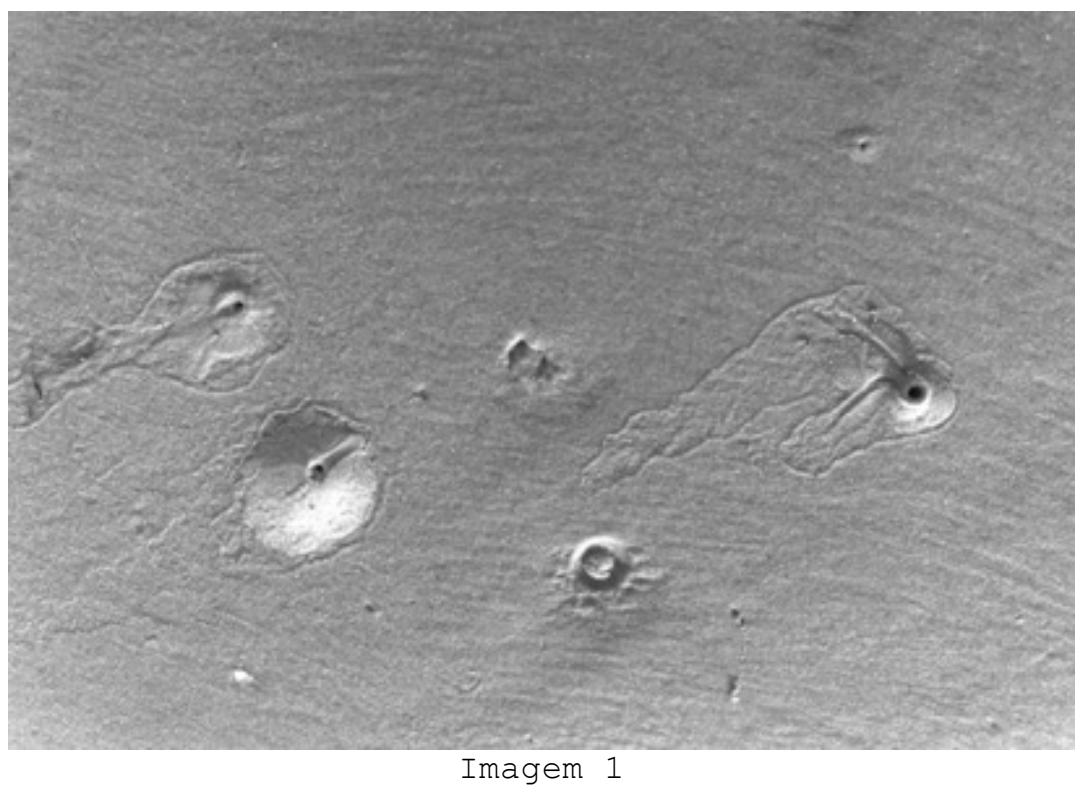

Fonte: arquivo pessoal

Os pequenos rastros deixados por essas espécies se tornam gestos que instauram a sua existência, sendo imanentes a ela. Nesse caso, "o modo não é uma existência, mas a maneira de fazer existir um ser em determinado plano" (LAPOUJADE, 2017, p. 15). Como comenta o autor, pode-se dizer que o modo (de modus) pensa a existência a partir dos limites ou medidas dos seres, enquanto que a maneira (de manus) pensa a existência a partir do gesto. Enquanto o modo limita a potência de existir, a maneira revela a forma do existir, sua linha ou sua curvatura singular, e assim mostra uma "arte". Diante de nós, aparece o desenho de inscrições, ao mesmo tempo, em harmonia e oposição aos buracos das tocas, em uma espécie de composição de contraste, de complementaridade ou de equilíbrio, surgidos a partir do interior do próprio fenômeno ocorrido na paisagem. Alguns dos movimentos deixados na areia permanecem em estado de rascunho, porém, outros se intensificam em variações infinitas, ganhando precisão em função de uma arte de existir até que outro momento natural (o movimento das marés, dos ventos) irrompe e o apaga, propondo outras e novas configurações que se superpõem e se misturam ao andarilharmos pela paisagem e suas bordas. 

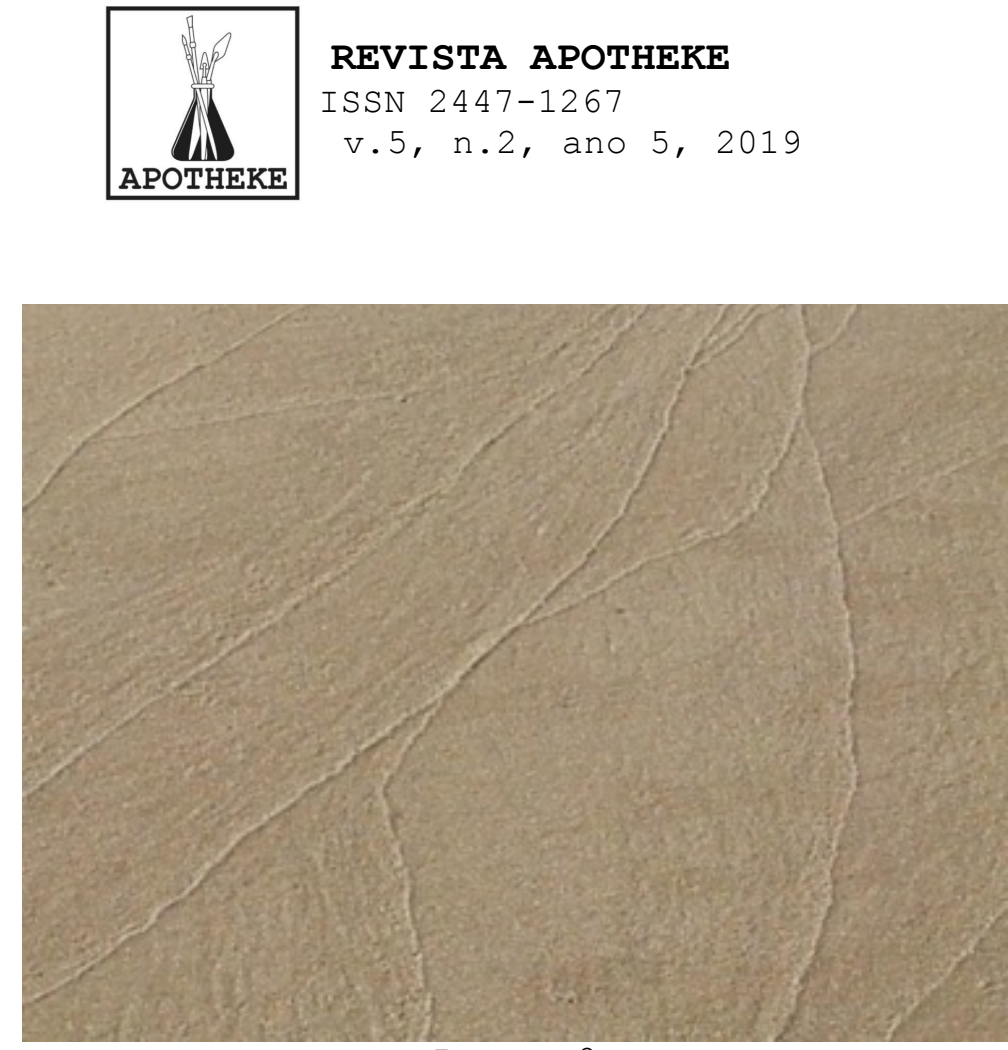

Imagem 2

Fonte: Arquivo pessoal

As coisas que não tem dimensões são muito importantes. Assim, o pássaro tu-you-you é mais importante por seus pronomes do que por seu tamanho de crescer. É no ínfimo que eu vejo a exuberância. (BARROS, 2010, p. 341)

Caminhar pela borda da areia que se estende e se entrega as ondas que avançam e se retraem num continuum nos coloca como rastreadores em meio a estados de experiências. A natureza nos oferece espaços e limites, condições de visibilidade e invisibilidade, mostra presenças que não são humanas, essas nos afetam, instigam nossa percepção, evidenciam diferenças que nos tocam sem precisarmos tocá-las, estão ali e ali permanecerão sem a nossa presença constituindo a vida. 


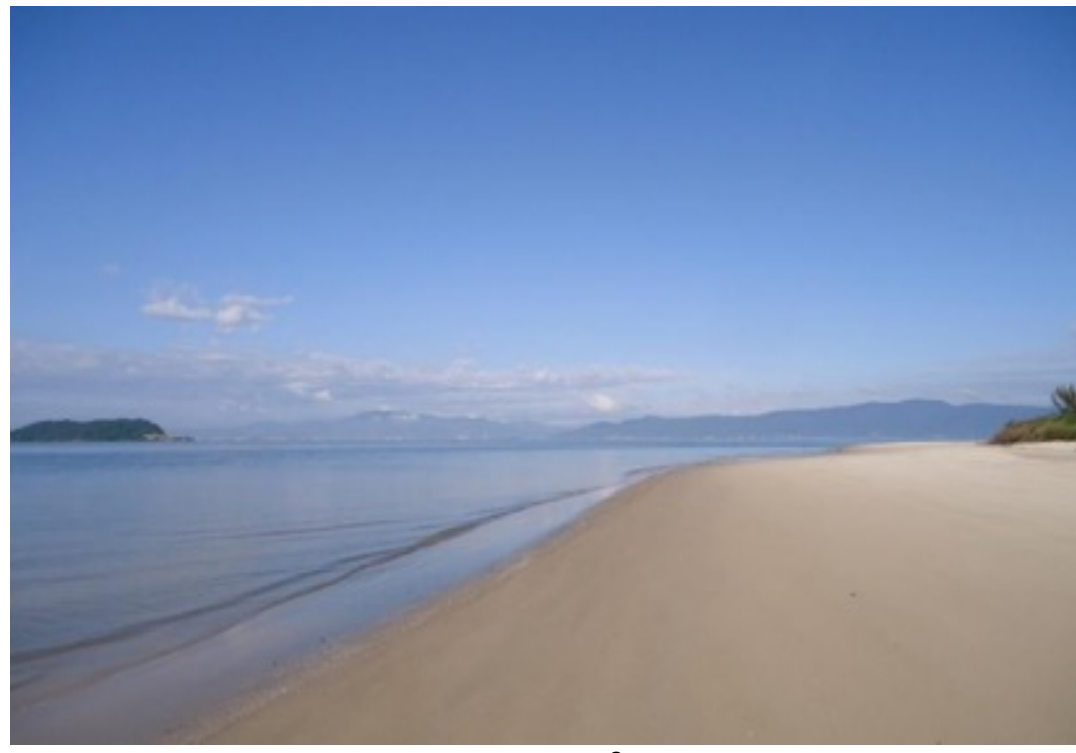

Imagem 3

Fonte: Arquivo pessoal

Ao caminhar, entre os passos dados e o olhar, acontece uma cadência compassada, a leitura do espaço acontece, porém, nem só com os olhos, como comenta Rebecca Solnit: "se o corpo é o registro do real, então ler com os pés é real de uma maneira que ler somente com os olhos não é" (2016, p.122). Aqui está presente a atenção interessada em busca de um encontro inusitado, um rastro ínfimo para a maioria das pessoas, ou sutil, por originar-se de seres quase invisíveis. O encontro com esse rastro ínfimo é também o encontro com o desenho. Aquilo que tanto buscamos, porque queremos sempre nos surpreender, porque está fora do nosso poder de ação, já aconteceu, está ali, é incrível, não é intuitivo, não é subjetivo nem objetivo, muito menos conceitual, é um fenômeno da natureza.

A racionalização de toda experiência naquele instante não dá conta daquele acontecimento, do estado de alegria que nos domina e transporta virtualmente para o ser infantil que mora em nós, para aí sim, vir à tona nossa condição humana, somos também rastro ínfimo, fenômeno da natureza, compondo em estado de devir, com o fenômeno. Porque essa apreensão do fenômeno 


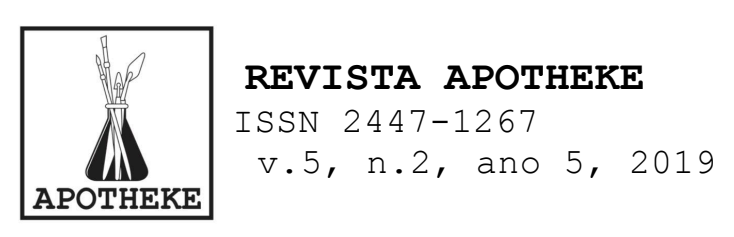

independe da consciência daquele que o percebe. Pois, "[...] o fenômeno tem uma maneira de se colocar ele mesmo, na sua perfeição própria que o distingue de qualquer outro modo de existência". (LAPOUJADE, 2017, p. 29)

O que a natureza desvela é uma configuração instantânea que lhe dá tonalidade e brilho singulares, tal qual momentos de graça da natureza, descritos em seu esplendor momentâneo, em que toda paisagem se recompõe por essa nuance. Assim, o encontro com esse outro inusitado, desenho a-humano, oferece ao artista caminhante evidências estéticas espaciais que formam pensamentos desviantes. Deixa-se naquele espaço de tempo todas as angústias e preocupações com o próprio fazer poético e entra-se no desvio a-humano passando a fazer relações com o desenho humano.

Por estarem em uma superfície em constante movimento, por menores que sejam, os pequenos seres desenhadores estarão sempre sujeitos ao movimento da maré. As ondas formam lindas linhas sinuosas que dependendo de suas forças se tornam mais ou menos volumosas formando o traço diferencial, denominado por Jacques Derrida, aquele traço que separa a mesma superfície em duas, pois é o traço que transborda permitindo a identificação e a percepção. O traço instaura sobre a superfície de um lugar ao mesmo tempo que delimita o espaço que atinge. Para Derrida, a experiência do traço e do rastro diferencial coloca um limite entre espaço, tempo, figuras, como condição de visibilidade e invisibilidade. Derrida comenta que:

o conceito de rastro [...] não tem limites, ele é coextensivo à experiência do vivo em geral. Não apenas do vivo humano como do ser vivo em geral. Os animais rastreiam, todo ser vivo rastreia. (DERRIDA, 2012, p.129)

Os pequenos seres, por mais leves que sejam, ao se movimentarem sobre a superfície de areia fina e úmida e 


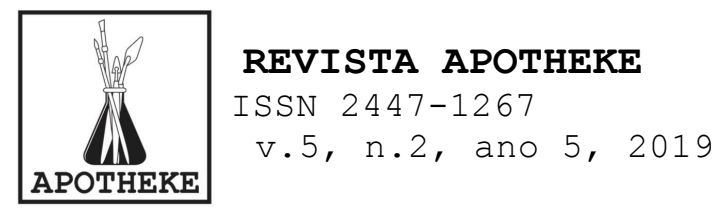

sujeitos à água, deixam marcas formando relevos aproximando-se da ideia de incisão. Derrida defende o enceguecimento do traço, este não é visto enquanto traço, mas como demarcador de território. Assim, podemos pensar que o traço incisivo ou o rastro na areia provocado pelo atrito dos pequenos seres com a superfície e a água é visto, no entanto o enceguecimento se dá em seu entorno, porque ali está o seu diferencial.

Que relação pode ter o desenho com o que acontece? Ou com quem chega? O que no desenho pode dar conta dessa irrupção imprevisível do que (de quem) acontece/chega? O desenhista é alguém que vê vir, que pré-desenha, que trabalha o traço, que calcula, etc., mas o momento em que isso traça, o movimento em que o desenho inventa, em que ele se inventa, é um momento em que o desenhista é de algum modo cego, em que ele não vê, ele não vê vir, ele é surpreendido pelo traço que ele trilha, pela trilha do traço, ele está cego. É um grande vidente, ou mesmo um visionário que enquanto desenha, se seu desenho constitui acontecimento, está cego. (DERRIDA, 2012, p.71)

Será possível aproximar o que defende Derrida quanto a cegueira do desenhista no momento em que traça o traço, do movimento que acontece entre o ínfimo ser vivo e a superfície úmida e absorvente da areia?

Por um lado, o desenho humano, na maioria das vezes, em sua performance corporal, é mediado por instrumentos que favorecem uma determinada gestualidade em traços, ora espontâneos ora controlados, mais finos ou grossos, delicados ou determinados e intensos, coloridos ou não. Por outro lado, - desenho desses seres marinhos mínimos nos aparece pelos seus impulsos corporais sobre a superfície junto ao movimento da água e da provocação dos ventos, como um surfista que se deixa levar pela onda acompanhando o seu movimento, mas muito pouco podendo fazer com seu corpo contra a força da água. O surfista não deixa rastros e é cego para o que deixou lá trás. O ser ínfimo deixa seus rastros por ser de uma outra ordem biológica, mas que, também, não viu o que rastreou. 


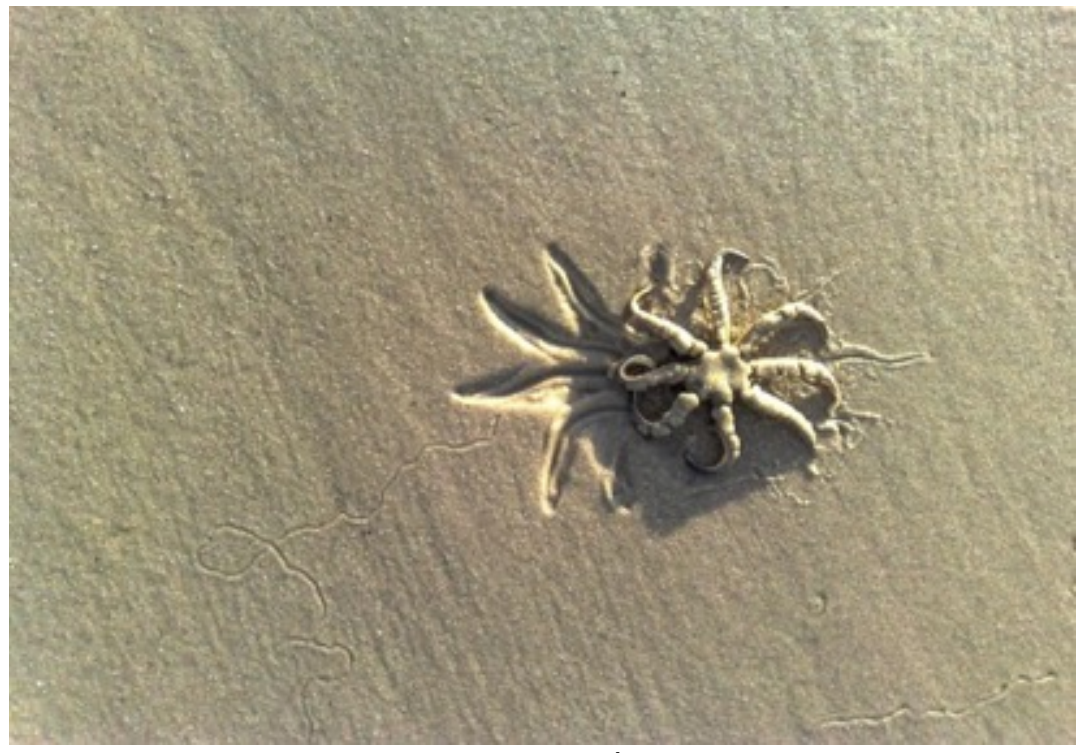

Imagem 4

Fonte: Arquivo pessoal

\section{Em superfície a transitoriedade dos desenhos}

Na superfície da areia, aparecem desenhos transitórios que desvelam um plano de existência singular que envolve um ponto de vista. "Souriau repete com frequência: é preciso encontrar o ponto de vista da coisa, pois cada modo de existência possui seu ponto de vista". (LAPOUJADE, 2017, p. 48)

Para encontrar esse ponto de vista, é preciso estar aberto a todas as potencialidades da experiência pura, e, paradoxalmente, a maior heterogeneidade possível, capaz de produzir metamorfoses ao caminhar pelas várias perspectivas oferecidas pela paisagem. Talvez, seja necessário o mesmo gesto ou ação do artista que precisa retomar a página ou a tela em branco, para recomeçar tudo, em uma experiência pura destinada a limpar a percepção para, desse modo, efetuar uma conversão do olhar. Trata-se de fazer ver, de tornar perceptível novas classes de seres, mesmo os invisíveis. Em um primeiro momento, o movimento consiste em empurrar para fora do plano qualquer forma de identidade ou interioridade preexistente que bloqueie a percepção. "Nem essência, nem forma de interioridade, partimos do grau zero da experiência 


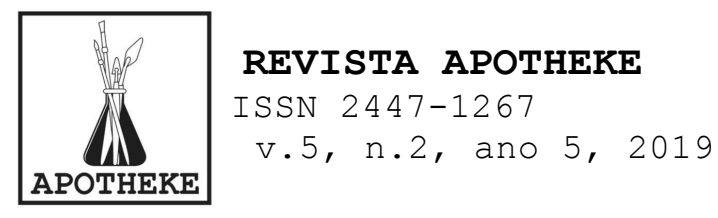

para fazer ver como se constituem as experiências vividas". (Idem, 2017, p. 50)

Talvez, estabelecer um plano que, se não fosse isso, seria invisível, para alcançar uma espécie de experiência pura que, a partir disso, permitiria a sua reconstituição. Tal como faz Hannah Nyala², rastreadora do Deserto de Mojave, que se deixa levar, distraidamente, pelos sinais mais diminutos da vida, fato que se transformou, para ela, em uma paixão incessante por seguir os rastros mais enigmáticos até algum lugar, qualquer lugar.

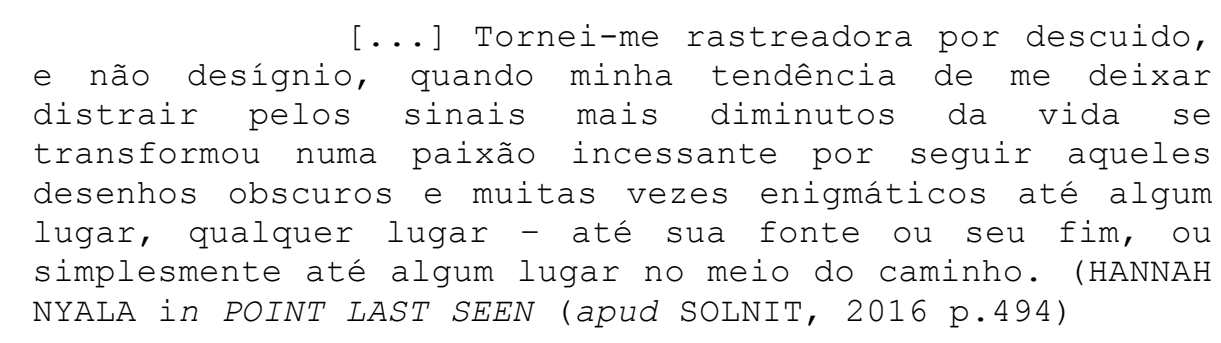

Para ela, seria como seguir os rastros em direção aos sinais diminutos da vida, tal qual o caminhante em uma prática artística na busca de rastros mínimos, mesmo que esses logo se dissipem. Breve aparição de uma pequena estrutura e dissipação. O que ocorre em nós como sensação é o "ruído do fenômeno"3 ${ }^{3}$. Esse "ruído" revela os sinais momentâneos da natureza, descritos como momentos singulares em suas linhas traçadas ao acaso pela maré, pelos ventos, ou pelo deslocamento de espécies, em puros instantes em si e por si. Outro modo de dizer que existe uma arte imanente ao fenômeno ocasionado na natureza.

\footnotetext{
2 Rastreadora, dedicada a salvar a vida dos perdidos, extremamente sintonizada com as mensagens da natureza de tal forma que ela pode ler a história de uma pegada, pistas em pedras e areias do deserto.

3 Lapoujade diz que o fenômeno não tem nada a ver com a sensação que é, para o autor, "o ruído do fenômeno", que na maioria das vezes apenas mistura e máscara o princípio formal que estrutura uma aparição. (2017, p. 29-30)
} 


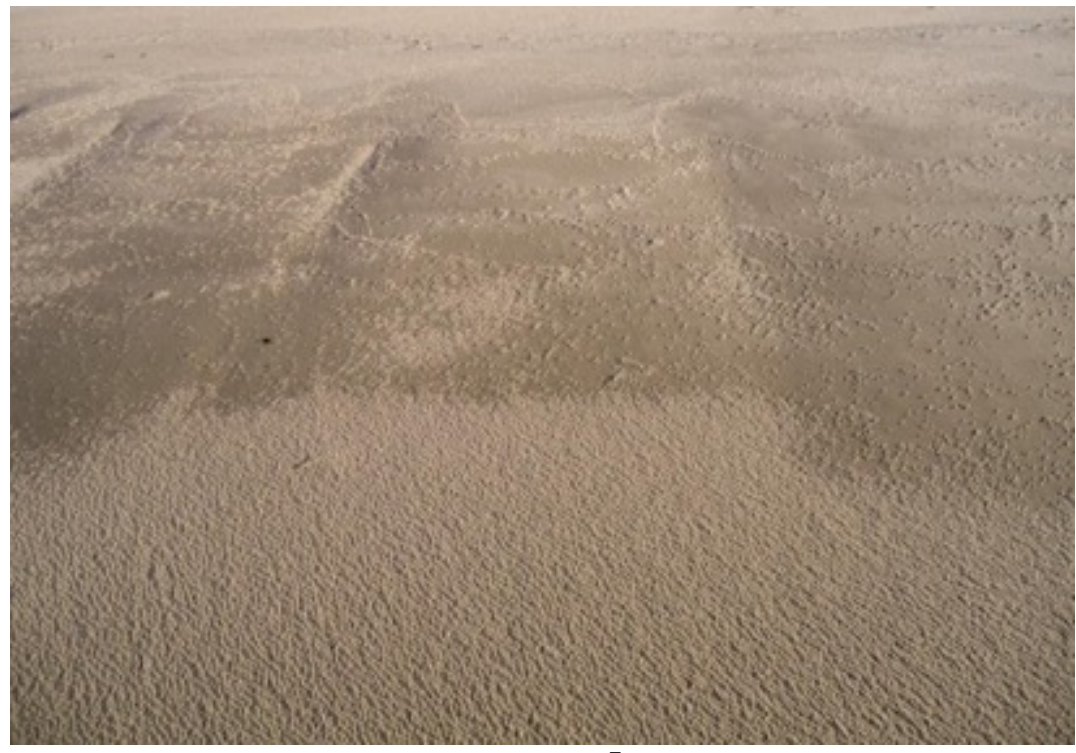

Imagem 5

Fonte: Arquivo pessoal

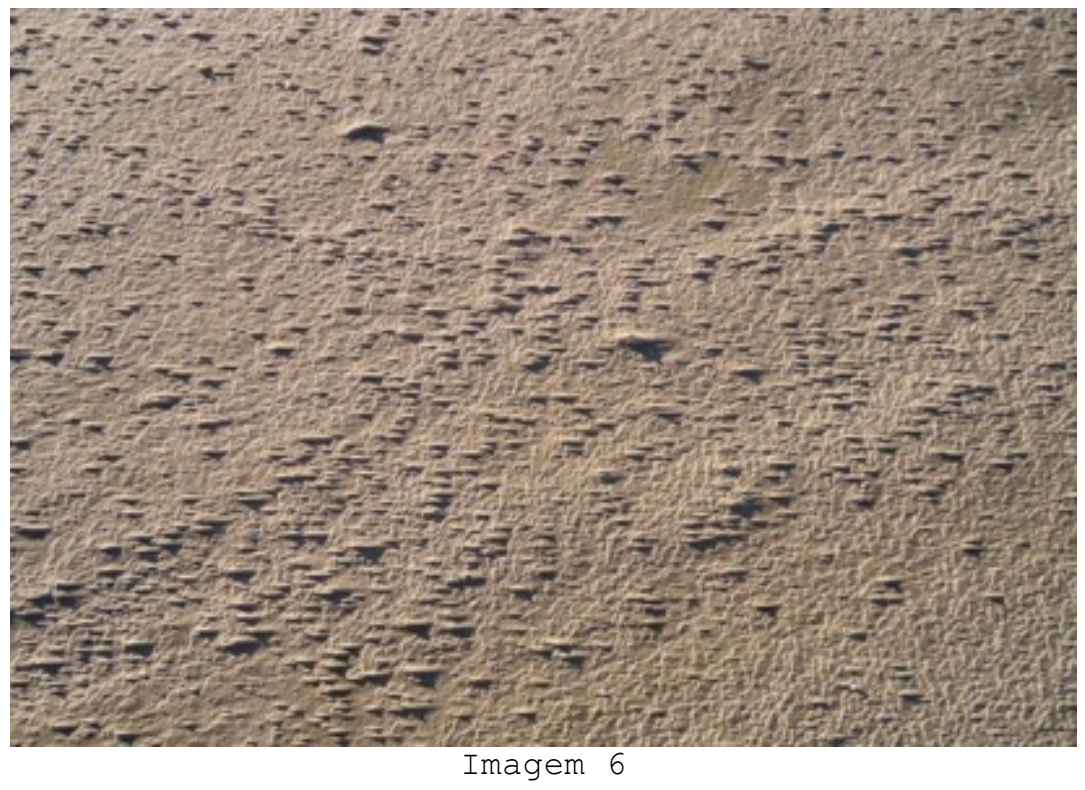

Fonte: Arquivo pessoal

Como fenômenos imanentes a arte, essas imagens ( 5 e 6) apresentam uma sequência de desenhos obscuros e enigmáticos de pontos de vista diversos que, sob essas condições, ativam uma quantidade de esboços ou de começos em torno de uma paisagem cambiante, realizadas pelo movimento caleidoscópico de seres que aparecem e desaparecem, deixando suas inscrições na areia da praia. Portanto, a perfeição de sua existência é ser sempre 


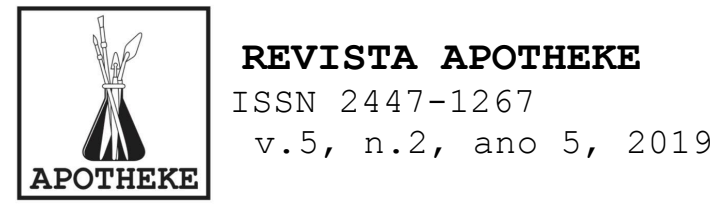

inacabada, ou seja, há algo como uma expectativa ou uma exigência de realização, que espera a arte para lhes dar uma existência maior. Como diria Lapoujade:

Eles esperam a arte que pode lhes dar uma existência maior e diferente. Sua arte é suscitar ou exigir a arte; seu "gesto" próprio é suscitar outros gestos. Eles precisam de outro ser - um criador - que agirá para que possam ter uma existência maior e diferente. Inversamente, o criador precisa dessa nuvem de virtuais para criar novas realidades, ele se alimenta de sua incompletude. Ou seja, são os virtuais que introduzem um desejo de criação, uma vontade de arte no mundo. Eles são a origem de todas as artes que praticamos. (2017, p. 38)

Nessa criação, os virtuais não constituem um universo à parte, separado do mundo real. Ao contrário, são imanentes ao mundo, pois não há uma realidade que já não esteja acompanhada de uma nuvem de potencialidade. Cada existência pode se tornar uma sugestão ou fragmento de outra realidade futura, portanto toda existência é legitimamente inacabada. Como explica Alliez, a partir da noção filosófica do atual e do virtual em Deleuze:

Não há objeto puramente atual. Todo atual rodeia-se de uma névoa de imagens virtuais. \{... É assim que uma partícula atual emite e absorve virtuais mais ou menos próximos, de diferentes ordens. Eles são ditos virtuais à medida que essa brevidade os mantém, consequentemente, sob um princípio de incerteza ou de indeterminação. Todo atual rodeia-se de círculos sempre renovados de virtualidades, cada um deles emitindo um outro, e todos rodeando e reagindo sobre o atual [...] (1996, p. 49)

Esse princípio de emissão de virtualidades que alteram e reagem sobre o atual segue no processo de Geórgia Kyriakakis ${ }^{4}$, problematizando a imaterialidade da própria imagem. A artista aponta para a transformação dos seus trabalhos denominados desenhos de pós (2007/12), indicando que há neles, apesar de

4 Artista visual, brasileira, formada em Artes Plásticas pela Fundação Armando Alvares Penteado, mestre e doutora em Artes pela Universidade de São Paulo (USP). 


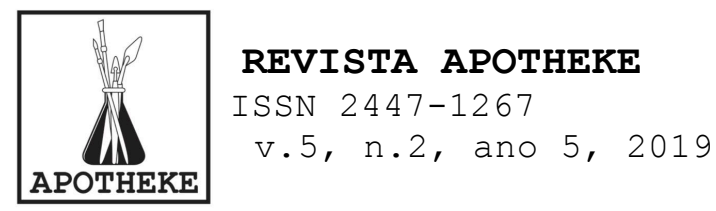

toda a materialidade de suas linhas, um quantum de impalpabilidade na imagem que ela cria, "o desenho se transforma para mim numa espécie de território, no qual a concretude das coisas e a imaterialidade da imagem é sempre problematizada" (2007, p. 161).

O seu posicionamento operacional manifesta-se entre a dinâmica do que é visivel e do que é inteligível. Mas sugere que o imaginário pode interferir no olhar que projeta sobre a paisagem quando comenta que:

Não seria esse olhar o responsável por exaurir das montanhas toda sua concretude para apreendêlas como uma silhueta, como um desenho que se estende num plano - também imaginário - extenso e sem profundidade? Ou ainda, o que constitui o nível do mar? Poderia a superfície da água ser concebida como uma espécie de membrana impalpável - e, portanto, desprovida de espessura material - que separa água do ar? Esse limite tênue não é determinado pelo peso físico das duas matérias? É possível visualizar tal superfície sem que o olhar penetre também na matéria? Quando a superfície da água reflete o mundo, ela não se torna simultaneamente perceptível e invisível? (DERDYK, 2007, p.162)

Nesse caso, trata-se de uma criação que parte de um material meio físico, meio mental, que, a partir de virtualidades, recarrega o desenho de potencialidades. Porém, não se trata de revelar no desenho uma forma pura ou nem mesmo atingir uma matéria pura. Na verdade, o que distingue o material de uma simples matéria é que ele é animado de forças, de dinamismos internos que fazem dele uma realidade viva. Portanto, o pó ou a areia não são matérias inertes, pois são compostas de micro grãos em dobras e nervuras constituídas, ao longo do tempo, pelos movimentos climáticos. Desse modo, tanto - artista quanto as inscrições na areia, seguem os vetores de força da intencionalidade do material em suas variáveis relações. Segundo Lapoujade, J. Dubuffet" comenta que "a arte deve nascer do material e da ferramenta e da luta da

5 Jean Dubuffet (31/07/1901 - 12/05/1985), escritor, artista, teórico do movimento estético art brut (arte bruta) - (Apud LAPOUJADE, 2017, p. 54) 


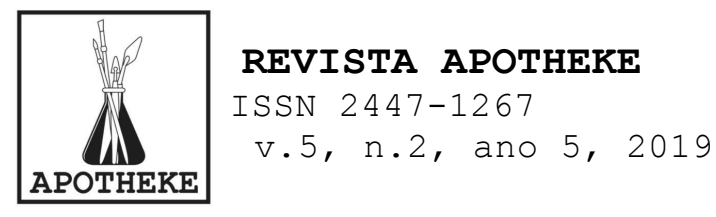

ferramenta com o material", em um encontro potencial que conduz a conexões inesperadas.

Inesperadas como as configurações dos desenhos na areia que remetem a um material composto, apto a transformações, em que pequenos seres se encontram com a matéria areia para, em estados cambiantes, se proliferar em linhas múltiplas.

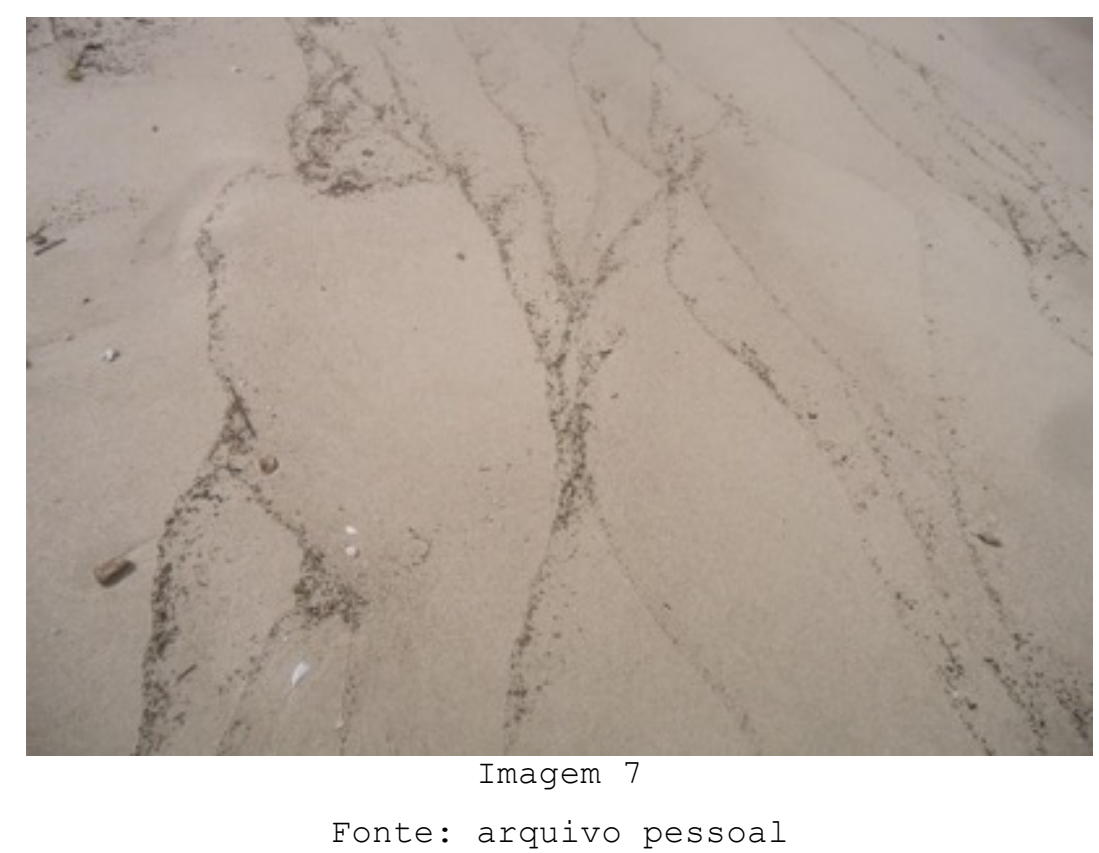

As linhas sinuosas formadas por resquícios de resíduos das marés ao tocar a areia apresentam algo indefinível, mas, ao mesmo tempo, uma forma palpável estampada na paisagem. Do encontro desses vetores, mar e areia, ocorre um "choque de forças entre o que ainda está no ar e o que já está concretizado na terra [...]" (DERDYK, 2012, p. 14)

Os resíduos que se apresentam junto as linhas de maré mostram outras perspectivas do desenho de superfície arenosa, esse desenho não emerge da areia, chega com a água, não está vivo, ao contrário, traz com sua aparição a lembrança da própria transitoriedade da existência e da vida.

\section{Referências}

ALLIEZ, Éric. Deleuze filosofia virtual. Tradução de Heloísa B. S. Rocha. São Paulo: Ed. 34, 1996. 
BARROS, Manoel de. Poesia completa. São Paulo: Leya, 2010.

DERDYK, Edith. Linha do horizonte: por uma poética do ato criador. São Paulo: Editora Intermeios, 2012

$\overline{2007 .}$ (Org.). Disegno. Desenho. Desígnio. São Paulo: Editora Senac,

DERRIDA, Jacques. Pensar em não ver: escritos sobre as artes do visível. Florianópolis: Ed. Da UFSC, 2012.

LAPOUJADE, David. As existências mínimas. Tradução de Hortencia Santos Lencastre. São Paulo: n-1 edições, 2017.

NYALA, Hannah. Point last seen: a woman tracker's story. New York: Pocketbook, 1997.

SOLNIT, Rebecca. A história do caminhar. São Paulo: Martins Fontes - selo Martins, 2016.

\section{Autores}

Elaine Schmidlin

Acesso ao CV: http://lattes.cnpq.br/9781556928615419

Professora no Programa de Pós-graduação e no curso de Licenciatura em Artes Visuais do Centro de Artes (CEART) da Universidade do Estado de Santa Catarina (UDESC). Possui Pós-doutorado pelo Instituto de Filosofia da Universidade Nova de Lisboa; Doutorado em Educação pela Universidade Federal de Santa Catarina (UFSC); Mestrado em Educação pela Universidade Federal do Paraná (UFPR) e Graduação pela Escola de Belas Artes da Universidade Federal do Rio de Janeiro (UFRJ). Integrante do Grupo de Pesquisa Entre Paisagens UDESC/CNPq.

ORCID: https://orcid.org/0000-0002-7478-1781

Sandra Maria Correia Favero

Acesso ao CV: http://lattes.cnpq.br/1656023214349642

Artista, pesquisadora e professora no Programa de Pós-graduação e nos cursos de Licenciatura e Bacharelado em Artes Visuais do Centro de Artes (CEART) da Universidade do Estado de Santa Catarina (UDESC). Possui Doutorado em Poéticas Visuais pela Escola de Comunicação e Artes da Universidade de São Paulo (ECA/USP); Mestrado em Gestão do Design/Engenharia de Produção e Sistemas da Universidade Federal de Santa Catarina (UFSC); Bacharelado - Pintura pela Escola de Música e Artes do Paraná (EMBAP/UNESPAR). Integrante do Grupo de Pesquisa Articulações Poéticas UDESC/CNPq.

ORCID: https://orcid.org/0000-0002-3730-488x

Artigo recebido no dia 13 de agosto de 2019 Aprovado em 18 de agosto de 2019. 